\title{
Industry regulation, fund characteristics, and the efficiency of Australian private health insurers
}

\author{
Lan Nguyen, Andrew C. Worthington ${ }^{1}$ \\ Department of Accounting, Finance and Economics, Griffith University, Nathan, QLD, Australia
}

\begin{abstract}
We examine the technical and scale efficiency of 30 Australian private health insurers during the period 2010-2017 using data envelopment analysis (DEA). We calculate industry pure technical efficiency of $91.6 \%$ and scale efficiency of $95.1 \%$. We also employ a two-stage DEA truncated bootstrapped regression to model efficiency on fund and policy factors. The results show that premium restrictions and risk-equalisation policies, and fund characteristics like size, but not for-profit/not-for-profit status, market share and leverage, exert significant effects. The findings suggest substantial scope for regulatory reform and structural change in the Australian private health insurance industry as a means of improving its efficiency.
\end{abstract}

Key words: Private health insurance; technical efficiency; scale efficiency; regulation JEL classification: D24; G22; I13

\footnotetext{
The authors would like to thank an anonymous reviewer, delegates at the $40^{\text {th }}$ Annual Australian Health Economics Society Conference in Hobart and the $31^{\text {st }}$ Annual Australasian Finance and Banking Conference in Sydney, and participants in a Finance and Financial Planning Research Seminar at Griffith University for their helpful comments.
}

Please address correspondence to Andrew Worthington via email: a.worthington@griffith.edu.au 


\section{Introduction}

Australia has a mixed public and private health care system, the primary component of which is Medicare, a compulsory universal health care scheme introduced in 1984. Funded through an income levy and general revenue, almost $68 \%$ of Australia's total annual health expenditure of $\$ 155$ billion is by Commonwealth and state and territory governments, with the remainder paid directly by users through out-of-pocket expenses $(18 \%)$, by private health insurers (8\%) and through accident compensation schemes (6\%) (Australian Institute of Health and Welfare, 2016). However, in spite of its relatively small share of total health expenditure, voluntary private health insurance plays an essential role in this system, with about half of all Australians holding some sort of private health insurance policy. Private health insurance in Australia also funds around one-third of all public and private hospital services and pays for a disproportionate share of primary and ancillary health care costs.

Consequently, most agree that without private health insurance, the Australian health care system as it stands would be unsustainable, and that without significant government intervention in the health insurance industry itself, it could fail to meet key social policy objectives, such as the equitable access to health care and better population health outcomes. It may also not adequately protect consumers by supervising insurance funds and addressing market failures inherent in many insurance markets, but especially health care, such as adverse selection, moral hazard and the lack of competition. These considerations account for the very heavy regulation of the private health insurance market in Australia, with extensive controls covering product and pricing approval, community ratings, insurance incentives, and fund solvency, as shown in Figure 1.

However, a number of government and industry reviews have identified aspects of these regulations that are likely to impede efficiency and therefore call into question its ability to deliver on desirable social and consumer outcomes. For example, some regulations affect how private health insurers can set premiums, including Ministerial pre-approval of premium changes. These can have consequences for competition in the private health insurance market, including discouraging entry and encouraging collusive behaviour (Deloitte Access Economics 2012; NCOA 2014). Together, these may potentially act against cost minimisation and premiums may rise as a result.

\section{$<$ INSERT FIGURE 1 HERE $>$}

Likewise, risk equalisation arrangements may reduce the incentive for insurers to innovate by developing and investing in health promotion strategies, chronic disease management 
programs, and other measures to improve customer health (NCOA 2014; PHIAC 2013). Lastly, content and benefit regulations have been criticised for locking insurers out of investing in products and services that could reduce the financial costs associated with hospital treatment. Examples of these foregone services include preventive health, early intervention, chronic disease management, and integrated care models.

Unfortunately, there is very limited existing work on the Australian private health insurance industry (Industry Commission, 1997; Carrington et al. 2011) to allow us to be in the position of gauging the impact of regulation and other factors on its efficiency and ability to innovate and become more productive. During the past decade alone, there has been significant change in the industry structure, with a move away from mostly small not-for-profit funds to the dominance of a very few large for-profit funds following the introduction of the Private Health Insurance Act (2007). There have also been considerable improvements in technology, the burgeoning costs of health services, and substantive changes in the nature of the insured pool with an ageing population (and the concomitant prospects for the care of age-associated chronic diseases like atherosclerosis and cardiovascular disease, cancer, arthritis, cataracts, osteoporosis, diabetes, hypertension, and Alzheimer's disease). These should all have substantial efficiency impacts on private health insurance funds.

Consequently, the objective of this paper is to assess the efficiency of the Australian private health insurance industry, both across time and funds, and to evaluate the possible impact of industry regulation and fund characteristics on efficiency. For this purpose, we employ data envelopment analysis (DEA), a nonparametric optimisation technique that models decision-making units (here insurance funds) as users of inputs and producers of outputs and one with already significant application in other health care services like hospitals, nursing homes, health management organisations, and physician practices (Worthington, 2004).

The remainder of the paper is organised as follows. Section 2 provides an overview of the Australian private health insurance industry. Section 3 presents the empirical methodology, including the models used and the specification of the input and output variables. Section 4 details the data and Section 5 discusses the results. Section 6 includes the concluding remarks and suggests some policy and practice recommendations.

\section{Overview}

As discussed, health care in Australia is a mixed system comprising both public and private sector health care. The public component is principally provided by Medicare as a government agency and is funded in part by a $2 \%$ levy on income (with exceptions for low-income earners), 
with any shortfall met by general revenue. Typically, Medicare covers most general practitioner and specialist services and all public in-hospital costs, but patients may also be entitled to other concessions or benefits once they have crossed a safety net threshold based on their total health expenditure. Where all or part of a particular service is not covered, patients must pay the balance (known as out-of-pocket expenses), unless entitled to subsidised access via a Health Care Card.

Private health insurance may also cover services not covered by Medicare as the principal funder apart from patients of private sector health care in Australia. Health care services typically provided by private health insurance include treatment as a private patient in a public or private hospital (known as hospital cover) and/or services not covered by Medicare such as physiotherapy, optometry, dental, and podiatry services (known as extras cover). Private health insurance cannot cover medical services provided out-of-hospital and already covered by Medicare. These include general practitioner visits, consultations with specialists and diagnostic imaging and tests. Private health insurance may also not cover the total cost of doctor services provided in hospital, which may then involve out-of-pocket expenses for even insured patients.

Since the introduction of Medicare in 1984, the Australian government has pursued a deliberate policy to encourage more Australians to purchase private health insurance, and has set in place specific policies aimed at either lowering private health insurance premiums for all policyholders and/or penalising high-income and older Australians without private health insurance. These include: the Private Health Insurance Incentives Scheme, including the Medicare Levy Surcharge and subsidies for premiums introduced from 1997-99; the Lifetime Cover scheme introduced on July 1, 2000; the Extended Medicare Safety Net introduced on March 1, 2004; and the Better Access Program created in 2006. Participation in private health insurance has varied considerably during this period as a result, but as at June 2018, 45.1\% and $54.3 \%$ of the population held hospital treatment and general treatment cover, respectively (APRA, 2018).

There are currently 37 private health insurers operating in Australia in the form of forprofit and not-for-profit insurers representing open access (available to all) or restricted access (open only to members of certain professional, industry and trade associations and unions) funds. Table 1 lists the 30 of these 37 insurance funds that have operated continuously during this period (excluding new entrants, closed funds, and funds with much missing data). Table 1 also identifies the eight for-profit funds ( $27 \%$ of funds) and the nine restricted access funds (30\% of funds). Unlike not-for-profit insurers, for-profit insurers pay income tax, but have 
greater flexibility in the use of fund assets under existing regulation, potentially improved access to capital, and additional monitoring by the Australian Stock Exchange for MPL as the sole publicly listed fund. Likewise, under existing regulations, private health insurers cannot refuse membership on the grounds of health status, age, or claims history, and outside lifetime cover conditions, and must charge the same premium for the same policy, even if they are a restricted fund. Currently, the market is dominated by the six-largest insurers (accounting for around $90 \%$ of all policies issued), with smaller insurers often operating in regional and state or other niche markets.

\section{$<$ INSERT TABLE 1 HERE $>$}

Apart from rebates aimed at directly affecting membership, the Australian government has enacted two main policies that potentially affect private health insurers during the period of this analysis. Both have a regulatory impact on the efficiency of the industry. The first is a premium policy, where under the Private Health Insurance Act (2007), the Commonwealth Minister for Health and Ageing and the Department of Health and Ageing plays a crucial role in the determination of private health insurance premiums.

Under this policy, all insurers may only annually apply to increase their premiums and have these approved. This premium setting process has been widely criticised, with claims that it lacks transparency, involves substantial uncertainty, has ill-defined criteria for assessment, and does not publicize the rationale for any decisions made. For example, one argument is that the premium policy encourages insurers to keep a higher level of costs than necessary in order to support future premium applications with uncertain approval outcomes (Deloitte Access Economics, 2012).

The second is the risk equalisation policy. Under this, a Risk Equalized Trust Fund operates to equalise the risk profiles of insurers, allowing the sharing of the costs of high-cost claims and claims for policyholders over 55 years of age across all insurers. Insurers either contribute or receive funds from the trust fund depending on their own risk profile. This has the benefit of potentially reducing the adverse effect of community ratings on insurers that have generally less healthy members. However, it is also not without criticism.

For instance, the Productivity Commission (2017) argues that "...while this (trust fund) may be equitable, it has the serious disadvantage of lowering the incentive to invest in preventative care, because any gains made by one insurer are shared with the others. Where insurers are investing in prevention, they could readily lose 50 cents for every dollar of benefit they obtain from avoiding health care costs, which must weaken the commercial viability of 
such actions". The focus of the trust fund on observed benefit payments also limits the incentive for insurers to manage benefit claims allocated to the risk equalisation pool (PHIAC, 2013).

\section{Methodology}

\subsection{Model}

We employ DEA, a technique widely used in the analysis of efficiency in the insurance industry, most often life and general (nonlife) insurance (Diacon et al. 2002, Worthington and Hurley 2002, Cummins and Xie 2008, Barros et al. 2010, Cummins et al. 2010, Mahlberg and Url 2010, Biener and Eling 2011, Huang and Eling 2013, Eling and Schaper 2017). A comprehensive survey of 95 studies applying frontier estimation methods in the insurance industry by Eling and Luhnen (2010) reveals that DEA is by far the dominant technique. Worthington (2004) provides a useful empirical survey of frontier estimation techniques as they apply to health care services.

Assume there are $N$ funds using $M$ inputs to produce $K$ outputs. We calculate a measure of input-oriented technical efficiency (TE) for the $j$-th fund for $j=1,2 \ldots N$ using the following linear programming problem:

$$
\begin{aligned}
& \mathrm{TE} j=\min \theta j \\
& \text { s.t. } \delta j X \leq \theta j x j \\
& \delta j Y \geq y j \\
& \delta j \geq 0(j=1,2,3 \ldots . N)
\end{aligned}
$$

where $\theta$ is a scalar providing a radial distance estimate for fund $j$, $Y$ is a $K \times N$ output matrix produced by the $N$ funds, $X$ is a $M \times N$ input matrix used by the $N$ funds, $y_{j}$ is a $K \times 1$ output vector and $x_{j}$ is a $M \times 1$ input vector for the $j$-th fund, and $\delta_{j}$ is an $N \times 1$ intensity vector for the $j$-th fund.

In the first part of our analysis, we calculate the fund efficiency scores under both constant returns-to-scale (CRS) and variable returns-to-scale (VRS) assumptions, corresponding to an assumption whether funds cannot or can change their scale (or size) of operations, respectively. One result is that VRS efficiency scores are typically higher. The efficiency scores range between zero and one, with a score of one being efficient. This provides useful relative scores of technical, pure technical and scale efficiency as well as identifying benchmark and better performing firms for further comparison.

The nonparametric nature of DEA has both advantages and disadvantages (Worthington, 2004). One advantage is that given its nonparametric basis, there is substantial freedom in the 
specification of inputs and outputs and the formulation of the production correspondence relating inputs to outputs. Another is that where the types of data necessary for other efficiency approaches are neither available nor desirable, the imposition of as few as possible restrictions on the data is likely to be most attractive. However, a disadvantage is that there is no (direct) accommodation for the types of bias resulting from environmental heterogeneity, external shocks, and specification and measurement error. Consequently, it judges the entire deviation from the frontier as the result of inefficiency. This may lead to either an under or overstatement of the level of inefficiency. In light of this, some critics of DEA have questioned the validity and stability of DEA measures of efficiency.

This is a particular problem in the second part of the analysis, in which we would like to explain the factors exogenous to our efficiency model and scores and their effect on efficiency. Typically, this involves regressing the scores from an efficiency analysis on these variables using ordinary least squares or Tobit regression. Simar and Wilson (2007) argue that using a conventional second-stage regression approach may lead to two additional problems. The first is the dependency of the efficiency scores because their calculation depends on the observation of all decision-making units (here insurance funds) in the same dataset. The second is the expectation of a strong correlation between the input, output, and exogenous variables. Therefore, direct regression analysis is invalid. As an alternative, using Monte Carlo experiments, Simar and Wilson (2007) propose a truncated bootstrapped regression model, which successfully overcomes the inference problems of conventional censored (Tobit) models for second-stage regressions and allows a methodologically robust analysis of the efficiency determinants.

Consequently, the Simar and Wilson (2007) truncated bootstrapped regression model has been widely applied in efficiency studies generally and in the insurance industry in particular, including by Barros et al. (2010), Biener and Eling (2011), and Biener et al. (2016). Accordingly, in the second analysis in this study, we evaluate the determinants of health insurance fund efficiency by employing the two-stage DEA approach and using the truncated bootstrapped regression proposed by Simar and Wilson (2007) to model the impact of firmlevel and environmental variables on the estimated bias-corrected efficiency scores.

\subsection{Inputs and outputs}

The next methodological requirement is to specify the theoretical production correspondence between inputs and outputs, for which there are three main approaches in the financial services sector: the asset (or intermediation) approach, the user-cost approach, and 
the value-added approach (Berger and Humphrey, 1992). We apply the value-added approach to our analysis. The inputs are variously labour, capital, business and service materials, with mostly agreement in the literature supporting this choice of inputs (Eling and Luhnen 2010). In line with production theory, the inputs of labour and materials are uncontentious. As for capital, in insurance firms, equity capital is an important input in efficiency analysis. One reason is that it enhances the financial quality of insurance products due to reducing the probability of default.

Another is that it is an essential component of the technology used to produce insurance products and services (Cummins et al., 2010). In support, Cummins and Xie (2013) examined scale economies in the US property liability insurance industry, reemphasizing that ignoring capitalization may lead to ambiguous and misleading results. However, because equity capital depends on for-profit/not-for-profit status, we also include debt capital, as also used in other insurance studies (Huang and Eling, 2013). Our health insurance fund inputs thus comprise: (i) management expenses (LAB) (including both labour and business services), (ii) debt capital (DBC), and (iii) equity capital (EQC). All other things being equal, insurance funds would prefer to use less of these inputs. Table 2 provides descriptions of the variables.

The outputs depend on the financial service offered. Cummins and Weiss (2000) identify risk pooling/bearing, intermediation and financial services as the main outputs of insurance firms in the value-added approach. For this, some use premiums or benefit payments to proxy as risk-pooling and risk-bearing outputs. For example, Adams et al. (2010) argue that it is rational to specify premiums or benefits as an output given they are both likely highly correlated with expected losses. Cummins et al. (2010) did likewise and found that premium- and loss-based efficiency scores were also highly correlated. However, Diacon et al. (2002) has criticised specifying benefits payments as an output as follows:

It is difficult to understand why the management of insurance companies would seek to maximize the value of insurance claims (particularly for general insurance), and this therefore violates the principle output characteristic identified by Cooper et al. (2000) that more output should be preferred to less.

For the intermediation function, we could use either invested assets (Cummins and Xie 2013, Yaisawarng et al. 2014) or investment income (Mahlberg and Url 2010, Carrington et al. 2011, Alhassan and Biekpe 2015). Nevertheless, as premiums correlate highly with the third function of insurer financial services, we would not typically model it as a separate output (Huang and Eling, 2013). As a result, in this study, we specify premium revenue (PMR) 
and investment revenue (INV) as outputs, given health insurers generally prefer to write more insurance business and to realise greater returns on their investment business, respectively.

\subsection{Explanatory variables}

The extant literature has documented the influence of many fund and industry factors on the efficiency of the insurance industry. See, for example, Diacon et al. (2002), Worthington and Hurley (2002), Luhnen (2009), Cummins et al. (2010), Barros et al. (2010), Biener and Eling (2012), Cummins and Xie (2013), Huang and Eling (2013), Alhassan and Biekpe (2015), Biener et al. (2016), and Eling and Schaper (2017). For instance, Huang and Eling (2013) evaluated the impact of macroeconomic (GDP growth, CPI, interest rates) and regulatory variables (regulated equity-to-asset requirements) and confirmed that environmental conditions indeed affect insurance industry efficiency. Similarly, Biener et al. (2016) examined the Swiss insurance industry and found that international diversification and firm size had a significant impact on fund efficiency.

We first specify two regulatory factors as explanatory variables in our analysis: (i) the rate of annual premium increase $(P R E)$ and (ii) the annual risk-equalized trust fund $(T F U)$. As discussed, these are contentious regulatory controls, as both vary by fund and have a possible adverse effect on fund efficiency. We are also particularly interested in the impact of fundspecific characteristics that potentially affect competition, performance, innovation and sustainability in the industry, and for this we specify: (iii) market share (MAR), (iv) fund type $(T Y P),(v)$ fund size $(S I Z)$, and (vi) leverage ( $L E V)$. Table 2 provides additional details.

\section{Data and descriptive statistics}

All data is publicly available from the Operations of Private Health Insurers Annual Reports produced by the Private Health Insurance Administrative Council (PHIAC) and since 1 July 2015 by the Australian Prudential Regulation Authority (APRA) under $\S 167$ of the Private Health Insurance (Prudential Supervision) Act 2015. These reports summarize the operations and financial activities of registered private health insurers for each financial year ending 30 June. We also collect the trust fund data from APRA, while the average annual premium increases for each fund are publicly available from the Australian Department of Health. As discussed, our sample comprises the 30 insurers operating over the period 201017. These collectively account for $98.7 \%$ of the market, so the sample is exceedingly representative of the Australian private health insurance market. We deflate all monetary values $(2010 / 11=100)$ using the health services price index from the Australian Bureau of Statistics. 


\section{$<$ INSERT TABLE 2 HERE $>$}

Table 2 provides selected descriptive statistics for all funds over the period $2010-17$. In terms of the outputs (in millions), average premium revenue (\$541.50) is much larger than average investment revenue $(\$ 13.30)$. The private insurance inputs show that equity capital is largest $(\$ 176.68)$ on average followed by debt capital $(\$ 146.07)$ and then management expenses (\$47.19). For the regulation-related explanatory variables, premium increases over the sample period range from $1.50 \%$ to $15.52 \%$, with an average of $5.48 \%$ per annum, while the dollar value of the trust fund set in place as a risk-sharing measure ranges from $-\$ 166.74$ to $\$ 167.84$. For fund-specific characteristics, the largest market share is $29.48 \%$, but the average market share is only 3.25\%. The fund size ranges from $\$ 8.6$ to $\$ 3,204.3$ million with an average of $\$ 114.7$ million, while the average debt-to-equity ratio is 0.59 . Finally, in terms of the coefficients of variation (not shown), there is most variation across the industry in trust fund (60.27), premium revenue (2.15), and market share (2.14), and least variation in the debtto-equity ratio (0.86), the rate of premium increases $(0.25)$ and fund size $(0.13)$.

\section{Results and discussion}

\subsection{Efficiency scores}

One requirement of DEA is to specify either an input or output-orientation, corresponding to an emphasis on either the equiproportionate reduction of inputs (the same outputs for fewer inputs) or the equiproportionate augmentation of outputs (more outputs for the same inputs), respectively. As a solution, Coelli (1996) argues that “...essentially, one should select orientation according to which quantities (inputs or outputs) the managers have most control over". On this basis, we believe the input-oriented approach is most appropriate because insurance fund managers operate within a highly regulated market regarding the price and quality of their services, and therefore have most scope for an input-minimising strategy. We use DEAP Version 2.1 to run the DEA programs in this first analysis.

Table 3 provides the overall technical, pure technical and scale technical efficiency scores for each fund, with funds ranked by asset size. A score of 1.000 indicates an efficient fund, with anything less being an inefficient fund. We also include whether a fund is experiencing increasing, constant, or decreasing returns-to-scale. For example, a fund may have an efficiency less than one, but this may be because it is either too small or too large, and increasing and decreasing returns-to-scale indicates whether it needs to increase or reduce its scale to become fully efficient, respectively. Under a CRS assumption, the results in Table 3 
show that the average overall technical efficiency (OTE) is 0.872 over the period. Put differently, the industry could reduce inputs by $12.8 \%(=1.000-0.872)$ of their current level were the production practices of the most efficient funds (those with efficiency scores of 1.000) applied throughout the industry. Of the 30 funds, only two (BUPA and Defence) are fully efficient $(\mathrm{OTE}=1.000)$ and the minimum level of efficiency is 0.699 .

\section{$<$ INSERT TABLE 3 HERE $>$}

Under the VRS assumption, the average pure technical efficiency (PTE) of the industry is 0.916 and therefore the efficiency gap is $8.4 \%(=1.000-0.916)$. As discussed earlier, PTE $>$ OTE because the assumption of VRS allows firms to alter their operational scale (usually not possible in the short run) to help improve efficiency (held constant under CRS), such that rearranging existing inputs at the existing scale (size) will be sufficient to reduce inefficiency to its optimal level. One outcome is that under VRS there are four times more fully efficient funds (BUPA, NIB, TFH, Defence, GBHS, Police, NHBA and RBHS) now defining the efficiency frontier $(\mathrm{PTE}=1.000)$. This suggests that technical efficiency is an important source of inefficiency in this industry and the restrictions placed on funds in the form of regulations governing the price and quantity of outputs may logically be the reason.

Table 3 also provides the scale inefficiency (SE) for each fund (where $\mathrm{SE}=\mathrm{OTE} \div \mathrm{PTE}$ ). The average SE score is 0.951 suggesting we could reduce inputs by $4.9 \%$ through improving the scale of funds in the industry using existing best practice. Once again, only two funds (BUPA and Defence) are fully scale efficient. As discussed, we can identify whether a fund is operating under increasing returns to scale (irs), constant returns to scale (crs), or decreasing returns to scale (drs) to establish the source of any scale inefficiency. The second-to-last column in Table 3 indicates that only six funds (20\%) are operating at a range consistent with crs (i.e. a proportional increase in outputs given an increase in inputs).

Remarkably, 19 funds (63\%) are operating at irs (i.e. a more than proportional increase in outputs given an increase in inputs). This suggests that nearly two-thirds of private health insurance funds are operating at too small a scale and could realise immediate and large gains by moving towards the scale efficient size based on the currently available technology. The figures in the final column demonstrate the clear relation with the dollar values of assets (admittedly an imperfect measure of the scale of any business), with the irs funds all having assets of less than about $\$ 400$ million. This broadly aligns with Biener et al. (2016) and their analysis of the efficiency of the Swiss life, property/casualty and reinsurance insurance industry 
and Luhnen's (2009) examination of the German property-liability insurance industry where most small funds were also found to be operating under irs.

In terms of increasing scale, there are two strategies available in practice. The first is organic growth. However, capturing market share in this mature and highly regulated industry will always be difficult, costly, and time-consuming. For example, after a decade of steady growth, membership is now falling across the industry and many firms are struggling to live with the lower growth in premiums (Boyd 2017). The obvious alternative is efficiency gains through merger. Already there are signs this is taking place. For example, in justifying a longmooted proposed merger of $\mathrm{HBF}$ and $\mathrm{HCF}$, the CEO of HBF stated that the health insurance market was ripe for consolidation with 35 percent of health funds collectively holding just an 8 percent market share (Boyd 2017). For his part, the CEO of HCF also supported the merger, declaring "This increased scale [would] enable us to increase our efficiency even further and that increased efficiency means more value for our members and more value with a combination of ensuring that we can keep our premiums as low as possible" (Han 2018). Nevertheless, with the proposal scrapped in June 2018, both HBF and HCF professed they had moved away from the merger in the interests of their respective members.

Our results also indicate that five funds (17\%) are operating at drs (i.e. a less than proportional increase in outputs given an increase in inputs). Three of these (MPL, HCF, and $\mathrm{HBF}$ ) are among the four-largest funds in the industry. At first impression, this recommends reducing the scale of some of the very largest funds through divestment or spin-offs. A better alternative is modifying the operational and regulatory conditions that impose significant constraints on these firms as they grow. For example, the sector is characterised by very modest growth in membership numbers, to some extent offset by more rapid premium increases in recent years. However, the government has also limited membership through means-testing private health insurance subsidies, and readdressing private health insurance affordability may be a way to improve the health of both the industry and the population.

Lastly, in results not shown, we identify some variation in efficiency outcomes in some years that appear to correspond to significant changes in the industry at the time. For example, in March 2012 and July and June 2014, DHF, CUA and Transport converted to for-profit funds, respectively. A merger between AHM and MPL was also completed in 2012/13, with the sale of MPL (the industry's second largest fund) announced in late 2013 and MPL listed on the Australian Securities Exchange in November 2014.

Something else that changed during this time concerned the chronic disease management program (CDMP) which has been operated to reduce complications in persons with diagnosed 
chronic disease and prevent the onset of chronic disease for a person with identified multiple risk factors for chronic disease. According to the PHIAC (2014), there was an overall decrease (31.4\%) in the number of these programs for 2013-14 over the previous fiscal year. One benefit of improved chronic disease outcomes are lower future claims costs associated with acute health intervention needs. Yet another possible influence was the introduction of means testing for the Private Health Insurance Rebate and an increase in the Medicare Levy Surcharge for high-income earners effective March 2012. In response, many policyholders prepaid their premiums to claim a rebate before the cut-off for the impending reform, with prepaid premiums increasing by $\$ 1.2$ billion across the industry during fiscal year 2011-12 (PHIAC, 2012). This increase in premium revenue provided a clear opportunity for insurers to earn additional investment revenue.

\subsection{Efficiency determinants}

In this subsection, we present the results of the truncated bootstrapped regression (Simar and Wilson, 2007) used to model the influence of the several industry and fund-level characteristics presented in Subsection 3.3 on the efficiency scores of funds. The empirical model is:

$$
T E_{i}=\beta_{0}+\sum \beta_{k} Z_{k i}+\varepsilon_{j} ; k=1, \ldots, n
$$

where $T E_{i}$ is the technical efficiency score of fund $i, Z_{k i}$ are the independent variables, $\beta_{0}$ and $\beta_{\mathrm{k}}$ are the estimated parameters and $\varepsilon_{\mathrm{i}}$ is the error term. In addition to the explanatory variables described earlier, we include the quadratic terms for fund size $\left(S I Z^{2}\right)$ and premium rate increases $\left(P R E^{2}\right)$ in the model in order to account for any nonlinear relationships between size $(S I Z)$ and premium rate increases (PRE) with efficiency. We use Stata Version 13 to estimate the Simar and Wilson (2007) truncated bootstrapped regression. For each coefficient, we estimate the bootstrap intervals using 2,000 bootstrapped estimates to obtain unbiased estimates. Table 4 presents the estimated coefficients and standard errors. As a robustness test, we estimate several different models by sequentially dropping particular variables. We find the results are consistent across all of the models, and so we restrict the remaining discussion to the full specification in Model 1. The Wald statistics in Table 4 evidence the sound goodnessof-fit of the regressions.

As shown in Table 4, there is a significant positive relationship between technical efficiency and premium rate increases $(P R E)$ and negative relationships between technical efficiency and trust fund (TFU) and fund size (SIZ). The estimated coefficients of fund type 
$(T Y P)$, leverage $(L E V)$ and market share $(M A R)$ are all insignificant. Returning to the statistically significant coefficients, the rate of premium increase $(P R E)$ exerts a significant effect on technical efficiency (at the 10\% level) and the negative sign and significance of the squared term $\left(P R E^{2}\right)$ indicates an inverted U-shaped relationship. In practice, there are three sources of premium rate increases being increases in claims, increases in management expenses, and decreases in fund profits, of which claims are the more important. Continual increases in claims could be challenging for funds. However, with a corresponding increase in premiums, the funds can increase their flexibility in covering the rise in benefit payouts, achieving higher outputs with the same input usages, thus improving efficiency. So allowing funds to increase their premium rates makes them more efficient. However, the U-shaped relationship with a maximum of $6.89 \%$ suggests that annual premium increases impact negatively on efficiency if too large.

\section{$<$ INSERT TABLE 4 HERE $>$}

One explanation for this is that funds will have no incentive to improve their risk management practices because of the protection offered by a too high premium. In addition, the unjustifiably high premium increases may result in policyholders dropping cover altogether or moving to another fund, and this could also negatively affect efficiency. For instance, some in the industry have blamed aggregator insurance sites for a similar effect in that aggregators, as with premium increases, encourage policyholders to change funds. The argument is that this simply raises costs for the industry as a whole because of the loss of scale in funds that lose customers and the cost of commissions of those that gain to encourage members to move from one fund to another (Boyd 2017).

For trust fund (TFU), we discern a significant negative impact on efficiency at the $1 \%$ level. As discussed, the trust fund in the Australian private health insurance industry operates as a risk-sharing measure to equalise industry-level outcomes. However, it could also serve as a disincentive for individual funds to control costs or invest in innovation because any improvement in the insurer's risk management would not return solely to that insurer, but shared across the industry with any benefits allocated across all the funds. While there are broader societal considerations regarding equity in cover, simply removing the trust fund may increase the incentive for insurers to reduce the number of older and sicker policyholders and attract younger and healthier policyholders. Where this is not feasible or wanted from the public policy perspective, the realisation is that this policy has a considerable negative effect on 
efficiency in the industry, and therefore represents a trade-off between fund profitability and sustainability and societal health care outcomes.

In terms of the remaining variables, fund size (SIZ) is significant negatively associated with efficiency, but the quadratic term $\left(S I Z^{2}\right)$ is positive and significant, with similar findings evident in Diacon et al. (2002) and Worthington and Hurley (2002) in the European and Australian insurance markets, respectively. Like our first analysis, this U-shaped relationship suggests smaller funds are indeed much less efficient through both combining inputs inefficiently and operating at a less than optimal scale (note that in this second analysis, the dependent variable is overall technical efficiency, which includes both pure technical and scale efficiency). The minimum of this U-shaped curve corresponds to about $\$ 119$ million in assets, indicating that nearly half of the funds in the Australian private health insurance market are too small to be in a position to improve their efficiency (both pure technical and scale efficiency). This seems to support arguments by industry participants of the significant scope for future consolidation in the industry.

\section{Concluding remarks}

In this paper, we examined the efficiency of Australian private health insurers during the period 2010-2017 and analysed the impact of industry and fund factors on efficiency using truncated bootstrapped regression. Overall, we revealed high levels of inefficiency in this highly regulated market. In terms of efficiency, we also found that most inefficiency was pure technical inefficiency. We also found relatively few fully efficient firms serving as the bestpractice frontier, and this suggests many firms are lagging in efficiency outcomes compared with their peers. Our first analysis revealed that there is significant scope for consolidation in the industry with nearly two-thirds of funds being too small to exploit optimal scale efficiency. Paradoxically, some of the industry's very largest funds are too big, and while this at first suggests breaking them up into smaller entities, we believe it results from the difficulty of achieving organic growth in what is now a mature, slow growing and highly regulated industry. Nonetheless, there remains significant scope for pure technical efficiency improvements, and our analysis identified a number of best-practice firms for detailed attention.

In terms of the drivers of inefficiency, we found that the heavy regulation of the industry is likely to involve a significant efficiency trade-off. While there are a number of possible potential policy instruments contributing to this, the restrictions placed on premium increases and the risk-sharing trust fund focused on in this analysis appear to play a significant role. We 
also found a U-shaped relationship with firm size suggesting policy needs to aim at increasing the size of funds in the industry, as nearly half are too small to achieve full efficiency gains. Interestingly, we found no significance difference between the efficiency of for-profit and notfor-profit funds, seemingly despite the former increasingly dominating the market through new entry and the demutualisation of existing funds.

These findings have several policy implications. With regard to the premium-setting process, allowing fund's flexibility to set premium increase would promote greater competition in the industry as funds have to compete with each other on price and adjust their own actions accordingly. This would encourage funds to attract consumers through innovation, product design, service quality, and other benefits. However, we believe that to maintain participation in private health insurance and preserve the industry's efficiency as a whole, there is still a need for a ceiling on premium increases and at least the maintenance of existing health insurance rebates. Future analysis of the price elasticity of demand for private health insurance would assist in this regard.

Concerning the risk equalisation trust fund regulation, we confirm it has a significantly negative effect on insurer efficiency. But once again, there is a difficult trade-off given its role in supporting community rating regulation and social policy by equalising the high claim costs of older and sicker policyholders across the industry, but at the cost of insurer-level inefficiency. One way to address this would be to impose a ceiling on the level of benefit payouts eligible for risk equalisation and to allow insurers leeway to invest in effective cost management programs to improve their consumers' health and reduce future claim costs. Analysing how changes in trust fund arrangements would affect the participation rate in private health insurance between, say, young and old policyholders, would then be a promising avenue for future research.

\section{References}

Adams, M., Kader, H. A. \& Hardwick, P. 2010, The cost efficiency of Takaful insurance companies, Geneva Papers on Risk and Insurance Issues and Practice, 35, 161-181.

Alhassan, A. L. \& Biekpe, N. 2015, Efficiency, productivity and returns to scale economies in the nonlife insurance market in South Africa. Geneva Papers on Risk and Insurance - Issues and Practice, 40, 493-515.

Australian Institute of Health and Welfare 2016, Australia's Health 2016. Australia's Health Series No. 15. Canberra. Available at: https://www.aihw.gov.au/getmedia/9844cefb-7745-4dd8-9ee2f4d1c3d6a727/19787-AH16.pdf.aspx.

Australian Prudential Regulatory Authority (APRA) 2015-2017, Operations of Private Health Insurance - Annual Reports. Available at: https://www.apra.gov.au/operations-of-privatehealth-insurers-annual-report 
Barros, C. P., Nektarios, M. \& Assaf, A. 2010, Efficiency in the Greek insurance industry. European Journal of Operational Research, 205, 431-436.

Berger, A. N. \& Humphrey, D. B. 1992, Measurement and efficiency issues in commercial banking. In Griliches, Z. (Ed.), Output Measurement in the Service Sectors, National Bureau of Economic Research, Studies in Income and Wealth, Vol. 56 (University of Chicago Press, Chicago).

Biener, C. \& Eling, M. 2011, The performance of micro insurance programs: A data envelopment analysis. Journal of Risk and Insurance, 78, 83-115.

Biener, C. \& Eling, M. 2012, Organization and efficiency in the international insurance industry: A cross-frontier analysis. European Journal of Operational Research, 221, 454-468.

Biener, C., Eling, M. \& Wirfs, J. H. 2016, The determinants of efficiency and productivity in the Swiss insurance industry. European Journal of Operational Research, 248, 703-714.

Boyd, T. 2017, Evidence of mounting pressure on not-for-profit health insurers, Australian Financial Review. Available at: https://www.afr.com/chanticleer/evidence-of-mounting-pressure-onnotforprofit-health-insurers-20171023-gz610d

Carrington, R, Coelli, T. \& Prasada Rao, D. 2011, Australian private health insurance productivity growth: Is there scope to limit premium increases? Economic Record, 87, 125-139.

Coelli, T. 1996, A Guide To DEAP Version 2.1: A Data Envelopment Analysis (Computer) Program. (Centre for Efficiency and Productivity Analysis, University of New England, Australia).

Cooper, W. W., Seiford, L. M. \& Tone, K. 2000, Data Envelopment analysis: A Comprehensive Text with Models, Applications, References, and DEA-solver software (Kluwer Academic Publishers, Boston).

Cummins, J. D. \& Weiss, M.A. 2000, Analyzing Firm Performance in the Insurance Industry Using Frontier Efficiency and Productivity Methods. In: Dionne G. (Ed.) Handbook of Insurance. Huebner International Series on Risk, Insurance, and Economic Security, Vol. 22 (Springer, Dordrecht).

Cummins, J. D., Weiss, M. A., Xie, X. \& Zi, H. 2010, Economies of scope in financial services: A DEA efficiency analysis of the US insurance industry. Journal of Banking \& Finance, 34, 15251539.

Cummins, J. D. \& Xie, X. 2008, Mergers and acquisitions in the US property-liability insurance industry: Productivity and efficiency effects. Journal of Banking \& Finance, 32, 30-55.

Cummins, J. D. \& Xie, X. 2013, Efficiency, productivity, and scale economies in the U.S. propertyliability insurance industry. Journal of Productivity Analysis, 39, 141-164.

Deloitte Access Economics 2012, Medibank: The Future of Private Health Insurance Premium-Setting: Seeking Integrative Solutions, Available at: https://www2.deloitte.com/content/dam/Deloitte/au/Documents/finance/deloitte-au-deloitteaccess-economics-medibank-private-report-november-2012-0112.pdf

Diacon, S.R., Starkey, K. \& O’Brien, C. 2002, Size and efficiency in European long-term insurance companies: An international comparison. The Geneva Papers on Risk and Insurance. Issues and Practice, 27, 444-466.

Eling, M. \& Luhnen, M. 2010, Frontier efficiency methodologies to measure performance in the insurance industry: Overview, systematization, and recent developments. Geneva Papers on Risk and Insurance Issues and Practice, 35, 217-265.

Eling, M. \& Schaper, P. 2017, Under pressure: how the business environment affects productivity and efficiency of European life insurance companies. European Journal of Operational Research, $258,1082-1094$.

Evaluate 2017, The Relative Efficiency of The Private Health Insurance Rebate v. Direct Public Health Expenditure, Report prepared for Private Healthcare Australia. Available at: https://www.privatehealthcareaustralia.org.au/wp-content/uploads/Evaluate-Report-RelativeEfficiency-of-PHI-Rebate-versus-Direct-Public-Health-Expenditure-1Aug2017.pdf. 
Han, E. 2018, What HCF and HBF's plan to merge means for health insurance customers, Sydney Morning Herald. Available at: https://www.smh.com.au/business/consumer-affairs/what-hcfand-hbf-s-plan-to-merge-means-for-health-insurance-customers-20180219-p4z0ud.html.

Huang, W. \& Eling, M. 2013, An efficiency comparison of the non-life insurance industry in the BRIC countries. European Journal of Operational Research, 226, 577-591.

Industry Commission 1997, Private Health Insurance, Report No. 57. (AGPS, Canberra). Available at: https://www.pc.gov.au/_data/assets/pdf_file/0006/156678/57privatehealth.pdf.

Luhnen, M. 2009, Determinants of efficiency and productivity in German property-liability insurance: evidence for 1995-2006. Geneva Papers on Risk and Insurance Issues and Practice, 34, 483505.

Mahlberg, B. \& Url, T. 2010, Single market effects on productivity in the German insurance industry. Journal of Banking \& Finance, 34, 1540-1548.

National Commission of Audit (NCOA) 2014, Towards Responsible Government: Appendix to the Report of the National Commission of Audit, Vol. 1, Canberra. Available at: https://www.ncoa.gov.au/sites/default/files/appendix_volume_1.pdf?acsf_files_redirect

Private Health Insurance Administrative Council (PHIAC) 2010-2014, Operations of Private Health Insurance - Annual Reports. Available at: https://parlinfo.aph.gov.au/parlInfo/search/summary/summary.w3p;page=0;query=PHIAC\%2 0annual\%20report\%20Decade\%3A\%222010s\%22;resCount=Default

Private Health Insurance Administration Council (PHIAC) 2013, Competition in the Australian Private Health Insurance Market, Research Paper 1, Canberra, 2013. Available at: http://www.thecie.com.au/wp-content/uploads/2014/06/130603-Competition-in-theAustralian-PHI-market-RP1.pdf

Productivity Commission 2015, Efficiency in Health, Commission Research Paper, Canberra, 2015, Available at: https://www.pc.gov.au/research/completed/efficiency-health

Productivity Commission 2017, Shifting the Dial: 5-Year Productivity Review, Inquiry Report No. 84. Available at: https://www.pc.gov.au/inquiries/completed/productivity-review/report.

Simar, L. \& Wilson, P. W. 2007, Estimation and inference in two-stage, semi-parametric models of production processes. Journal of Econometrics, 136, 31-64.

Worthington, A. C. \& Hurley, E. V. 2002, Cost efficiency in Australian general insurers: A nonparametric approach. British Accounting Review, 34, 89-108.

Worthington, A.C. 2004, An empirical survey of frontier efficiency measurement techniques in healthcare services. Medical Care Research and Review, 61, 1-36.

Yaisawarng, S., Asavadachanukorn, P. \& Yaisawarng, S. 2014, Efficiency and productivity in the Thai non-life insurance industry. Journal of Productivity Analysis, 41, 291-306. 
Regulation of content and benefit payments

Private health insurers cannot cover out-of-hospital services that are currently listed on the Medicare Benefits Schedule and funded by the Australian Government. This includes much of primary care, such as general practitioner visits. Regulations are also imposed on the content and minimum benefits of insurance policies. Insurers must use prostheses on the Prostheses List, and pay a set level of benefits for prostheses, to be eligible for government rebates.

Ministerial approval of premiums

Private health insurers must apply to the Minister for Health for approval of any change in premiums. The Minister may disallow a change deemed to be not in the public interest.

Community rating

Community rating prohibits private health insurers from varying premiums according to a customer's health risk (including lifestyle factors such as smoking or diet), sex, race, sexuality, previous claims history or age (excluding aged entry under Lifetime Health Cover). Insurers must also renew a policy regardless of the customer's health profile.

Risk equalisation

The Risk Equalisation Trust Fund is used to share the cost of 'high-cost' claims, and claims for customers over 55 years of age, across all private health insurers (on an ex-post basis). This reduces the financial impact of community rating on insurers with customers who are riskier or sicker than average.

Lifetime Health Cover

Annual premiums for hospital cover are increased for people who take out private health insurance after the age of 30, at a rate of 2 per cent for each year of deferral (up to a maximum of 70 per cent). The loading is removed once a customer has held insurance for 10 continuous years. The Private Health Insurance Rebate does not apply to this component of premiums.

Medicare Levy Surcharge

The Medicare Levy Surcharge is imposed on high-income earners who do not hold private health insurance (earning over $\$ 90000$ a year for singles or $\$ 180000$ for families). The rate varies with income from 1.0 to 1.5 per cent of taxable income.

Private Health Insurance Rebate

Most Australians holding private health insurance receive a rebate on premiums. The rebate is approximately 30 per cent for most taxpayers, but varies according to age (older taxpayers receive a higher rebate of almost 40 per cent) and income (the rebate falls to zero for those on the highest incomes).

Portability requirements

Private health insurers are prohibited from penalising consumers that switch insurers or switch policies with the same insurer. This means that consumers do not need to re-serve waiting periods to access benefits. These rules only apply to hospital cover.

\section{Source: Productivity Commission (2015, p. 66)}

Figure 1 Main policy instruments affecting private health insurance in Australia 
Table 1

Australian private health insurance funds

\begin{tabular}{|c|c|c|c|}
\hline Abbreviation & Fund name & For-profit & $\begin{array}{c}\text { Restricted } \\
\text { access }\end{array}$ \\
\hline ACA & ACA Health Benefits Fund Ltd & & $\sqrt{ }$ \\
\hline AUHL & Australian Unity Health Ltd & $\sqrt{ }$ & \\
\hline BUPA & Bupa HI Pty Ltd & $\sqrt{ }$ & \\
\hline CBHS & CBHS Health Fund Ltd & & $\sqrt{ }$ \\
\hline $\mathrm{CDH}$ & Cessnock District Health Benefits Fund Ltd & & \\
\hline CUA & CUA Health Ltd & & \\
\hline Defence & Defence Health Ltd & & $\sqrt{ }$ \\
\hline DHF & Doctors' Health Fund Pty Ltd & $\sqrt{ }$ & $\sqrt{ }$ \\
\hline GMHBA & GMHBA Ltd & & \\
\hline GUC & Grand United Corporate Health Ltd & $\sqrt{ }$ & \\
\hline HBF & HBF Health Ltd & & \\
\hline $\mathrm{HCF}$ & Hospitals Contribution Fund of Australia Ltd & & \\
\hline $\mathrm{HCI}$ & Health Care Insurance Ltd & & \\
\hline HIF & Health Insurance Fund of Australia Ltd & & \\
\hline HP & Health Partners Ltd & & \\
\hline Latrobe & Latrobe Health Services Ltd & & \\
\hline Mildura & Mildura District Hospital Fund Ltd & & \\
\hline MPL & Medibank Private Ltd & $\sqrt{ }$ & \\
\hline Navy & Navy Health Ltd & & $\sqrt{ }$ \\
\hline NHBA & National Health Benefits Australia Pty Ltd & $\sqrt{ }$ & \\
\hline NIB & NIB Health Funds Ltd & $\sqrt{ }$ & \\
\hline People Care & People Care Health Ltd & & \\
\hline Phoenix & Phoenix Health Fund Ltd & & \\
\hline Police & Police Health Ltd & & $\sqrt{ }$ \\
\hline QTUH & Queensland Teachers' Union Health Fund Ltd & & $\sqrt{ }$ \\
\hline RBHS & Reserve Bank Health Society Ltd & & $\sqrt{ }$ \\
\hline St Luke's & St Luke's Medical and Hospital Benefits Association Ltd & & \\
\hline $\mathrm{TFH}$ & Teachers Federation Health Ltd & & $\sqrt{ }$ \\
\hline Transport & Transport Health Pty Ltd & $\sqrt{ }$ & \\
\hline West Fund & West Fund Ltd & & \\
\hline
\end{tabular}


Table 2

Variables and descriptive statistics

\begin{tabular}{cllrrrr}
\hline Variable & \multicolumn{1}{c}{ Description } & Specification & \multicolumn{1}{c}{ Mean } & \multicolumn{1}{c}{ Std. dev. } & \multicolumn{1}{c}{ Min. } & \multicolumn{1}{c}{ Max. } \\
\hline PRM & Premium revenue (\$A mil.) & Output & 541.50 & $1,163.36$ & 7.89 & $4,881.56$ \\
INV & Investment revenue (\$A mil.) & Output & 13.30 & 25.47 & 0.15 & 155.15 \\
EQC & Equity capital (\$A mil.) & Input & 176.68 & 292.78 & 5.16 & $1,408.35$ \\
DBC & Liabilities (\$A mil.) & Input & 146.07 & 311.35 & 0.92 & $1,474.18$ \\
LAB & Management expenses (\$A mil.) & Input & 47.19 & 100.17 & 0.84 & 434.30 \\
PRE & Premium increase (\% change) & Explanatory & 5.48 & 1.39 & 1.50 & 15.52 \\
TFU & Trust fund (\$A mil.) & Explanatory & 0.73 & 44.00 & -166.74 & 167.84 \\
MAR & Market share (\% of policies issued) & Explanatory & 3.25 & 6.96 & 0.03 & 29.48 \\
TYP & Fund type (for-profit/not-for-profit) & Explanatory & 0.25 & 0.43 & 0.00 & 1.00 \\
SIZ & Fund size (natural log of total assets) & Explanatory & 11.65 & 1.54 & 9.06 & 14.98 \\
LEV & Leverage (debt/equity ratio) & Explanatory & 0.59 & 0.51 & 0.12 & 2.49 \\
\hline
\end{tabular}


Table 3

Efficiency scores, returns-to-scale, and assets

\begin{tabular}{|c|c|c|c|c|c|}
\hline Fund & OTE & PTE & SE & RTS & Assets \\
\hline MPL & 0.936 & 0.981 & 0.955 & $\mathrm{drs}$ & 3,209 \\
\hline BUPA & 1.000 & 1.000 & 1.000 & crs & 2,086 \\
\hline $\mathrm{HCF}$ & 0.956 & 0.995 & 0.960 & drs & 2,082 \\
\hline $\mathrm{HBF}$ & 0.801 & 0.871 & 0.919 & drs & 1,764 \\
\hline NIB & 0.981 & 1.000 & 0.981 & crs & 756 \\
\hline TFH & 0.963 & 1.000 & 0.963 & drs & 463 \\
\hline AUHL & 0.863 & 0.901 & 0.959 & irs & 395 \\
\hline Defence & 1.000 & 1.000 & 1.000 & crs & 394 \\
\hline GMHBA & 0.803 & 0.876 & 0.917 & drs & 351 \\
\hline CBHS & 0.992 & 1.000 & 0.992 & crs & 287 \\
\hline Latrobe & 0.787 & 0.858 & 0.917 & irs & 213 \\
\hline Westfund & 0.699 & 0.705 & 0.990 & irs & 192 \\
\hline $\mathrm{HP}$ & 0.902 & 0.957 & 0.942 & irs & 150 \\
\hline QTUH & 0.864 & 0.903 & 0.956 & irs & 128 \\
\hline HIF & 0.757 & 0.828 & 0.915 & irs & 121 \\
\hline GUC & 0.744 & 0.770 & 0.967 & irs & 112 \\
\hline St Luke's & 0.814 & 0.890 & 0.914 & irs & 111 \\
\hline Peoplecare & 0.874 & 0.948 & 0.922 & irs & 106 \\
\hline Navy & 0.893 & 0.953 & 0.936 & irs & 102 \\
\hline CUA & 0.905 & 0.981 & 0.923 & irs & 102 \\
\hline Mildura & 0.937 & 0.989 & 0.947 & irs & 92 \\
\hline Police & 0.998 & 1.000 & 0.998 & crs & 76 \\
\hline DHF & 0.831 & 0.900 & 0.923 & irs & 60 \\
\hline $\mathrm{ACA}$ & 0.871 & 0.922 & 0.945 & irs & 27 \\
\hline Phoenix & 0.795 & 0.862 & 0.923 & irs & 24 \\
\hline $\mathrm{HCI}$ & 0.726 & 0.755 & 0.961 & irs & 20 \\
\hline Transport & 0.752 & 0.801 & 0.939 & irs & 20 \\
\hline NHBA & 0.961 & 1.000 & 0.961 & irs & 17 \\
\hline RBHS & 0.972 & 1.000 & 0.972 & crs & 14 \\
\hline $\mathrm{CDH}$ & 0.776 & 0.832 & 0.932 & irs & 10 \\
\hline Mean & 0.872 & 0.916 & 0.951 & - & 449 \\
\hline Std. dev. & 0.093 & 0.085 & 0.028 & - & 777 \\
\hline Max. & 1.000 & 1.000 & 1.000 & - & 3,209 \\
\hline Min. & 0.699 & 0.705 & 0.914 & - & 10 \\
\hline$\#$ eff & 2 & 8 & 2 & - & - \\
\hline$\%$ eff & 6.67 & 26.67 & 6.67 & - & - \\
\hline
\end{tabular}

Notes: Ranked by assets in descending order; OTE - overall technical efficiency, PTE - pure technical efficiency, SE - scale efficiency, RTS - returns-to-scale; irs - increasing returns-to-scale, crs - constant returns-to-scale, drs - decreasing returns-to-scale; assets in \$ millions; figures in bold denote fully efficient. 
Table 4

Truncated bootstrapped regression coefficients

\begin{tabular}{|c|c|c|c|c|c|}
\hline Variables & Model 1 & Model 2 & Model 3 & Model 4 & Model 5 \\
\hline \multirow{2}{*}{ PRE } & $0.028^{*}$ & $0.029 * *$ & $0.029^{*}$ & $0.029 *$ & $0.029 * *$ \\
\hline & $(0.015)$ & $(0.015)$ & $(0.015)$ & $(0.015)$ & $(0.014)$ \\
\hline \multirow{2}{*}{$\mathrm{PRE}^{2}$} & $-0.002 *$ & $-0.0021 * *$ & $-0.002 * *$ & $-0.002 * *$ & $-0.002 * *$ \\
\hline & $(0.001)$ & $(0.001)$ & $(0.001)$ & $(0.001)$ & $(0.001)$ \\
\hline \multirow{2}{*}{ TFU } & $-0.001 * * *$ & $-0.002 * * *$ & $-0.002 * * *$ & $-0.002 * * *$ & $-0.002 * * *$ \\
\hline & $(0.001)$ & $(0.001)$ & $(0.001)$ & $(0.001)$ & $(0.001)$ \\
\hline \multirow{2}{*}{ MAR } & 0.004 & & 0.004 & 0.004 & (2 \\
\hline & $(0.003)$ & - & $(0.004)$ & $(0.003)$ & - \\
\hline \multirow{2}{*}{ TYP } & 0.005 & 0.007 & - & 0.005 & - \\
\hline & $(0.031)$ & $(0.031)$ & - & $(0.020)$ & - \\
\hline \multirow{2}{*}{ SIZ } & $-0.961 * * *$ & $-1.016^{* * *}$ & $-0.958 * * *$ & $-0.960 * * *$ & $-1.021 * * *$ \\
\hline & $(0.117)$ & $(0.087)$ & $(0.118)$ & $(0.115)$ & $(0.085)$ \\
\hline \multirow{2}{*}{$\mathrm{SIZ}^{2}$} & $0.041 * * *$ & $0.044 * * *$ & $0.041 * * *$ & $0.041 * * *$ & $0.044 * * *$ \\
\hline & $(0.005)$ & $(0.004)$ & $(0.005)$ & $(0.005)$ & $(0.004)$ \\
\hline \multirow{2}{*}{ LEV } & 0.001 & -0.001 & 0.004 & & 0.005 \\
\hline & $(0.029)$ & $(0.027)$ & $(0.018)$ & - & $(0.016)$ \\
\hline \multirow{2}{*}{ Cons. } & $6.195 * * *$ & $6.487 * * *$ & $6.179 * * *$ & $6.190 * * *$ & $6.515 * * *$ \\
\hline & $(0.656)$ & $(0.510)$ & $(0.662)$ & $(0.646)$ & $(0.495)$ \\
\hline Wald $\mathrm{Chi}^{2}$ & 150.16 & 156.01 & 147.11 & 143.66 & 156.22 \\
\hline Prob. $>$ Chi $^{2}$ & $<0.01$ & $<0.01$ & $<0.01$ & $<0.01$ & $<0.01$ \\
\hline Obs. & 210 & 210 & 210 & 210 & 210 \\
\hline
\end{tabular}

Notes: Variable descriptions in Table 2. Standard errors in brackets. $* * *, * *, *$ denote statistical significance at the $1 \%, 5 \%$, and $10 \%$ level, respectively. 